ESTRATEGIAS PICTOFÓNICAS.

UN ESTUDIO COMPARATIVO DE EFICACIA EN LA ENSEÑANZA DE LA LECTURA INICIAL PARA EL PRIMER GRADO DE EDUCACIÓN GENERAL BÁSICA EN SEIS ESCUELAS PÚBLICAS EN CARTAGO, COSTA RICA

ESTRATEGIAS PICTOFONICAS. A COMPARATIVE STUDY EFFECTIVENESS IN THE TEACHING OF EARLY READING FIRST GRADE FOR GENERAL BASIC EDUCATION IN SIX PUBLIC SCHOOL IN CARTAGO, COSTA RICA

Volumen 11, Número 2

pp. 1-33

Este número se publicó el 30 de agosto de 2011

María de los Ángeles Carpio Brenes

La revista está indexada en los directorios:

LATINDEX, REDALYC, IRESIE, CLASE, DIALNET, DOAJ, E-REVIST@S,

La revista está incluida en los sitios:

REDIE, RINACE, OEI, MAESTROTECA, PREAL, HUASCARAN, CLASCO 


\title{
ESTRATEGIAS PICTOFÓNICAS. UN ESTUDIO COMPARATIVO DE EFICACIA EN LA ENSEÑANZA DE LA LECTURA INICIAL PARA EL PRIMER GRADO DE EDUCACIÓN GENERAL BÁSICA EN SEIS ESCUELAS PÚBLICAS EN CARTAGO, COSTA RICA
}

\author{
ESTRATEGIAS PICTOFONICAS. A COMPARATIVE STUDY EFFECTIVENESS IN THE \\ TEACHING OF EARLY READING FIRST GRADE FOR GENERAL BASIC EDUCATION IN SIX \\ PUBLIC SCHOOL IN CARTAGO, COSTA RICA
}

\section{María de los Ángeles Carpio Brenes ${ }^{1}$}

\begin{abstract}
Resumen: Este es un artículo que presenta los resultados de un estudio experimental, que se hizo para contrastar la eficacia en la enseñanza de la lectura, en primer grado de Educación Básica, con las estrategias pictofónicas, método que estimula un proceso dual de aprendizaje de la lectura mediante la asociación del grafema con el dibujo que lo representa (proceso logográfica) y el fonema con la palabra clave (proceso alfabético); en tres escuelas públicas costarricenses (grupo experimental), frente al método ecléctico, propuesto por el Ministerio de Educación Pública (MEP) aplicado en otras tres escuelas públicas (grupo cuasi control) del Núcleo Uno, Circuito 05 de la Región Educativa de Cartago, Costa Rica. Para comprobar la adquisición, en cinco meses, de una mejor decodificación de sílabas y palabras, mediante el dominio de las reglas de correspondencia grafema-fonema, se aplicaron, en febrero y junio de 2010, subpruebas de cuatro test de lectura: LEA, P.E.R.E.L, PROLEC y LEE. Los análisis evidencian que se obtuvo, no sólo una mejor decodificación por parte de los estudiantes del grupo experimental, sino también un mejor desempeño en la segmentación fonética y una mayor generalización hacia nuevas combinaciones silábicas, por lo que se concluye que las estrategias pictofónicas son eficaces para la enseñanza de la lectura.
\end{abstract}

Palabras clave: LECTURA INICIAL, FONÉTICO, CONCIENCIA FONOLÓGICA, COSTA RICA.

\begin{abstract}
This article presents the results of a experimental study that was made to contrast the effectiveness in teaching of the reading in first grade with the estrategias pictofónicas (pictorial-phonic strategies), method that encourages a dual process oflearning to read by associating the grapheme with the picture that represents (logographic process) and the phoneme with the keyword (alphabetic process); in three costarrican elementary schools (experimental group), against the método ecléctico (eclectic method), proposed by the Ministry of Public Education (MEP), applied in other three public elementary schools (compare group) of Sector One, Circuit 05 of Cartago Educative Region, Costa Rica. To verify the acquisition in five months, of a better syllables and word decoding, through the domain of the correspondence rules of grapheme-phoneme, was applied in February and June of 2010 subtest of four lecture tests: LEA, PEREL, PROLEC y LEE. The results evidence that it was obtained, not only a better decoding by the students of the experimental group, but also a better performance of the phonetic segmentation and a much better generalization to the new syllabic combinations so, the study concluded that the estrategias pictofónicas (pictorial-phonic strategies) are effective for the teaching of the writing.
\end{abstract}

Key words: INITIAL READING, PHONETIC, PHONOLOGICAL AWARENESS, COSTA RICA.

\footnotetext{
1 Licenciada en Educación Especial y Máster en Psicopedagogía. Docente de la Escuela de Orientación y Educación Especial, Universidad de Costa Rica. Doctoranda (2009-2012) en Psicología Evolutiva y de la Educación, Universidad Autónoma de Madrid, España.
}

Dirección electrónica: marycarpiob@gmail.com

Artículo recibido: 05 de mayo, 2011

Aprobado: 28 de julio, 2011 


\section{Introducción}

Este artículo muestra los resultados de la aplicación, durante el primer semestre del curso lectivo 2010, de las estrategias pictofónicas en la enseñanza de la lectura inicial en estudiantes de primer grado del Núcleo Uno, Circuito 05 de la Región Educativa de Cartago, Costa Rica.

El tema es relevante, porque la validación de este conjunto de estrategias permitirá, en un futuro, proponerlo a docentes costarricenses como un método para la enseñanza de la lectura, fundamentado en teorías psicolingüísticas recientes y diseñado según los modelos de aprendizaje de hoy, que promueven la enseñanza directa de las letras y sus sonidos correspondientes (Barrio, 2007).

Por lo anterior, el propósito del artículo es mostrar los resultados que obtuvieron, durante cinco meses de enseñanza de la lectura, estudiantes de primer grado que fueron instruidos con las estrategias pictofónicas en comparación con otros estudiantes del mismo nivel que recibieron el método ecléctico. Se hace un recorrido histórico sobre la enseñanza de la lectura en Costa Rica, se describen los dos métodos contrastados, se explica el referente teórico, y se detalla la metodología aplicada en la investigación, para que el análisis de resultados y las conclusiones tengan el fundamento suficiente para proponer las estrategias pictofónicas como posible opción para la enseñanza de la lectura en el país.

\section{Referente teórico}

Al realizar un recorrido histórico por los diferentes métodos de lectura utilizados en Costa Rica, Rojas y Aguilar (2006) nos recuerdan que el primer uso documentado de un método para enseñar a leer se remonta a la Cartilla, que era un cuadernillo impreso que seguía el Método del Abecedario, y el Catón, que era un libro con textos elementales para la ejercitación de la lectura, utilizado en la época colonial y dirigido a la clase dominante. Sin embargo, sólo seis años después de la Independencia (1821) ya existían 50 escuelas que, en 1844, consiguen que exista un $10 \%$ de la población alfabetizada (Ministerio de Educación Pública/OEI, 1997), un porcentaje similar al de España, que era de 9,6\% en el primer censo de 1841 (Viñao, 2009).

En 1901, se encargó al lingüista y profesor Carlos Gagini, la redacción de la serie llamada El Lector Costarricense, constituido por cuatro textos breves, muy ilustrados, que incluía una enseñanza de la lengua a partir de procesos inductivos, donde las lecciones iniciaban presentando una o varias ilustraciones etiquetadas con el vocabulario a estudiar y organizadas 
en campos conceptuales. Desde entonces, cabe afirmar que los métodos de enseñanza de la lectura en los centros públicos, han sido de corte silábico y/o global.

Así, desde 1905 se utilizó el Silabario Costarricense, obra de Napoleón Quesada, que se dividía en dos partes, la primera daba la información básica para la lectura y la escritura, utilizando todas las letras del abecedario; y la segunda contenía lecturas para ejercitar el aprendizaje.

En 1908 apareció el Silabario Castellano, de Porfirio Brenes Mesén, que empleaba un método analítico-sintético con palabras y frases normales, que enfatizaba en la fonética del alfabeto, luego las sílabas y por último la lectura (Rojas y Villalobos, 1995).

En 1936, apareció publicado y declarado texto oficial, el Nuevo Silabario, de la doctora Emma Gamboa, inspirado en el método global o decrolyano, donde la enseñanza de la lectura comenzaba por el todo, es decir, con la oración, luego con las palabras, las sílabas y finalmente las letras que las constituyen. Los temas se tomaban de aspectos parciales de la vida del estudiante y su relación con la escuela, la casa, la naturaleza.

En 1960, y siguiendo el mismo enfoque global, Gamboa (1962) diseñó el primer texto de enseñanza de la lectura totalmente ilustrado a colores e impreso en Costa Rica, Paco y Lola, donde las oraciones estaban arregladas en series alrededor de un elemento principal, que se repetía varias veces de manera que el estudiante lo aprendía por repetición, siempre relacionándolo con su significado. El docente introducía cada aprendizaje nuevo de forma gradual, de la oración a la frase, de la frase a la palabra y, por último, al reconocimiento de la sílaba que se descubría por asociación en series de palabras.

A finales de la década del 60 , se iniciaron los proyectos de libros de textos oficiales, entendidos como aquellos en cuyo proceso de elaboración y distribución ha estado presente el Ministerio de Educación Pública de Costa Rica (MEP). Entre 1968 y 1978, se llevó a cabo el Programa ODECA-ROCAP (Organización de Estados de Centroamérica y Panamá), mediante el cual se dotó de libros de texto a las escuelas públicas del área. Estos incluían las guías para uso del docente, pero no eran específicos del país.

En 1985, el MEP inició un nuevo programa de elaboración de libros de texto, con el financiamiento de la Agencia Internacional para el Desarrollo de Estados Unidos. El producto fue la serie de libros Hacia la Luz, que abarcó las cuatro asignaturas básicas de cada año escolar de primaria. El de la asignatura de español incluía conocimientos generales de la lengua y la literatura. 
Durante los dos primeros años de existencia del programa se distribuyeron, aproximadamente, dos millones de libros en las escuelas públicas, pero la serie no se reimprimió, lo que favoreció el incremento de la circulación de libros de editoriales privadas, nacionales y extranjeras (Rojas y Aguilar, 2006).

Los desafíos que el contexto internacional estaba presentando con la llegada del nuevo milenio, dieron origen en 1994, a una nueva política educativa que pretendía eliminar la visión cortoplacista de los años de administración de cada gobierno, para reemplazarla por una visión de largo plazo que demandara de las autoridades políticas, de los profesionales de la educación y de la comunidad en general, un compromiso con el desarrollo integral de los jóvenes adultos del siglo XXI. Con el Decreto № 23489-MEP del 11 de julio de 1994, se establece la modernización del Ministerio de Educación Pública bajo el marco de la Política Educativa hacia el siglo XXI (Ministerio de Educación Pública, 1994).

En el año 1995, como respuesta a las demandas de esta nueva política educativa, el MEP, con la colaboración de la Universidad de Costa Rica, llevó a cabo una reforma de programas de la Educación General Básica y Diversificada, a partir del cual, en 1996, se elaboró la serie Hacia el siglo XXI, que incluía materiales desde la primaria hasta el tercer año de secundaria. Cada nivel de primaria se integra en un conjunto de libros denominado Complejo Didáctico: Texto, Actividades y Guía didáctica, de manera que se pusieron a disposición de las escuelas del país. Los libros de Español 1 y 2 (R. de Chacón y García, 1996), enfatizan la adquisición de la lectoescritura mediante el método ecléctico.

Éste método ha sido propuesto y desarrollado en el país a partir de 1970 (R. de Chacón, 1994), pero por su condición flexible, se ha actualizado y enriquecido a través de los años y tiene carácter obligatorio en el año 2010 mediante el oficio DM 3011-06-09 suscrito por el Ministro de Educación Pública. Su nombre, Ecléctico, se debe a que considera aspectos positivos de otros métodos anteriores y los integra en sus planteamientos metodológicos, técnicas y recursos para el aprendizaje, como una filosofía conciliadora. Sin embargo, se fundamenta especialmente en el método global, sistematizado en 1904 por el belga Ovidio Decroly, quien concibió la lectura como un acto global y fundamentalmente visual, donde lo esencial es reconocer globalmente las palabras u oraciones, para luego analizar las partes que las componen, sin importar la dificultad auditiva que presenten.

Con el método ecléctico se pretende formar individuos autónomos y conscientes de la importancia de la lectura como factor de desarrollo de su personalidad, por medio de lo que R. 
de Chacón (1994) llama el lector independiente, que es aquel sujeto que en forma gradual y paulatina ha logrado acceder a una serie de destrezas que le permiten, por sí solo, buscar información, interpretarla, organizarla y analizarla. La gradación de esas destrezas se organiza en lo que ella denomina Etapas del Lector Independiente, las cuales están dispuestas de manera ascendente y correlacionada con los niveles de la primaria costarricense como se explica a continuación.

La Etapa de Aprestamiento es fundamental, porque estimula las destrezas cognoscitivas, socioafectivas y motrices básicas para el aprendizaje de la lectoescritura, razón por la cual le asigna al Nivel de Preescolar la atención de estas áreas (Chaves, 2002).

En la Etapa de Iniciación se empieza el aprendizaje formal y sistemático de la lectoescritura, por lo que corresponde con el I grado de primaria. En el Desarrollo Rápido, que incluye en II y III grados, los estudiantes adquieren mayor soltura, fluidez, seguridad y claridad en la lectoescritura. La Lectura Amplia es un "despertar", como cita su autora, a la lectura en general, destreza que se da en IV y V grados de primaria; y en la Etapa de Refinamiento, los estudiantes de VI grado, aumentan y refinan sus capacidades para la lectura y escritura.

A pesar de esta secuencia de habilidades en lectura que deben aprender los estudiantes en su paso por las escuelas costarricenses, el Decimoquinto Informe Estado de la Nación en Desarrollo Humano Sostenible, sistema de seguimiento del desempeño de Costa Rica, mediante la selección, medición y evaluación de un conjunto de componentes del Desarrollo Humano Sostenible que cubren aspectos sociales, económicos, ambientales y políticos del desarrollo, informa que

a la luz de las condiciones que muestran las estadísticas costarricenses del 2006, según las cuales el $16,3 \%$ de los estudiantes reprobó el primer grado, el $27,8 \%$ el sétimo y el $20,8 \%$ de los jóvenes de entre 13 y 17 años no asistía a la educación secundaria, resulta imperativo prestar atención a las prácticas y a las metodologías utilizadas para la enseñanza de la Lengua. (Programa Estado de la Nación, 2009, p. 87)

En esta declaración de estrategia educativa nacional es que se enmarca este trabajo, toda vez que en este momento resulta oportuna esta investigación, ya que, al fundamentarse conceptual y teóricamente, el método ecléctico en un enfoque global, no parece estar en concordancia con los conocimientos actuales en el campo del aprendizaje de la lectura, porque 
enfatiza el reconocimiento de las palabras en una ruta léxica, que consiste en mirar la palabra, reconocer su configuración visual a partir de sus elementos gráficos más sobresalientes y, acceder a su representación en el léxico mental, que contiene el conocimiento sobre el deletreo y la pronunciación del encadenamiento de los grafemas que forman las palabras (Coltheart, 2007); dejando de lado la ruta no léxica, que involucra el uso de reglas de segmentación ortográfica hasta la segmentación fonológica, y el acceso al significado cuando se trata de palabras conocidas.

Las investigaciones psicológicas actuales sobre el reconocimiento de palabras muestran que cuando el niño o niña llega al período de la lectura, aporta ya un gran número de destrezas fonológicas, semánticas y ortográficas que proceden de su experiencia con el lenguaje oral, que se convierten, según Serrano (2005), en precursores del lenguaje escrito y predictores de la posterior adquisición lectora.

Entre esas habilidades está la capacidad de aislar mentalmente los fonemas, proceso que conlleva no sólo la conciencia fonológica, que se desarrolla en una etapa prelectora entre los 4 y 5 años cuando logran segmentar una palabra en sílabas, sino que requiere la segmentación en fonemas, denominada conciencia fonémica, que es una destreza más compleja que debe ser estimulada en el proceso de enseñanza de la lectura (Alegría, Carrillo y Sánchez, 2005).

La propuesta metodológica de las estrategias pictofónicas, se ubican en esta tendencia pues, basadas en la teoría de Phillip Seymour (2003) del modelo dual de desarrollo ortográfico, enfatizan la interacción entre la adquisición de la lectura y el desarrollo metalingüístico, como proceso simultáneo, que debe ser sistemáticamente enseñado en el contexto de aprendizaje de la lectura, de tres maneras (Alegría, Carrillo y Sánchez, 2005).

Explícita, porque el docente ayuda al estudiante a comprender la relación que existe entre grafemas y fonemas sin esperar que éste descubra espontáneamente tal relación; sistemática, porque la enseñanza se organiza siguiendo un orden preciso, determinado por consideraciones teóricas y prácticas que toman en cuenta las dificultades que plantea el aislar ciertos fonemas; y temprana, debido a que el código alfabético se presenta desde el comienzo de la instrucción.

Estas características son las que motivaron a llamarlo estrategias en lugar de método, pues corresponden a una serie de orientaciones metodológicas de enseñanza de la lectura, y no un conjunto de instrucciones cerradas que deben cumplirse literalmente. Están organizadas en etapas y fases, no sucesivas sino simultáneas, que permiten la interacción constante entre el 
desarrollo del sistema ortográfico y las representaciones fonológicas, tal y como se describe a continuación.

La Etapa Perceptual estimula la lectura logográfica de carteles del ambiente, con el propósito de propiciar el reconocimiento y almacenamiento de palabras familiares, como es el caso de los rótulos de DAMAS y CABALLEROS que se encuentran en las puertas de todos los baños públicos; la conciencia fonológica léxica y silábica, prerrequisito para adquirir la decodificación, indispensable para el proceso alfabético; y la presentación de las vocales, que inicia el proceso de correspondencia grafema-fonema al plantear la asociación del pictograma con la letra, y el sonido inicial de la palabra clave con el fonema.

La Etapa de Decodificación propone tres fases. La conciencia fonémica, para la introducción de las letras consonánticas y sus correspondientes sonidos; la fusión silábica para enseñar a los estudiantes las reglas de correspondencia grafema-fonema que les permite decodificar los diferentes tipos de sílabas según la posición de los grafemas; y la lectura y dictado de palabras, para estimular la conciencia fonológica.

La Etapa de Comprensión guía a los estudiantes en la comprensión lectora desde la primera serie silábica, con oraciones sencillas formadas con las sílabas conocidas. Para el desarrollo del procesamiento semántico, se acompañan las oraciones con ilustraciones que estimulan la construcción de representaciones mentales del contenido. El proceso sintáctico que se estimula en la Etapa de Redacción enfatiza la estructuración de oraciones a partir del esquema de sujeto-verbo-predicado, mediante clave de color y pictogramas.

Como las estrategias pictofónicas se enmarcan dentro de los enfoques evolutivos del aprendizaje de la lectura, pretenden promover un cambio relevante en el contexto educativo costarricense, pues, como señala Chaves (2004, p. 26), en los métodos para enseñar a leer que han tenido mayor influencia en Costa Rica, "sobresale una persona que aprende como receptora de un conocimiento proporcionado desde afuera, donde el protagonista es la educadora o el educador y el método, y no la persona que conoce".

Lo anterior justifica, de manera teórica, la posible efectividad de las estrategias pictofónicas en la enseñanza de la lectura, pero la validez práctica de su sistematización es lo que motiva la puesta en marcha de esta investigación, cuyo objetivo es comprobar, experimentalmente, la adquisición, a corto plazo, de una mejor decodificación de sílabas y palabras, mediante el dominio de las reglas de correspondencia grafema-fonema, por parte de 
los estudiantes instruidos con las estrategias pictofónicas en comparación con el método ecléctico. En consecuencia, se espera satisfacer las siguientes hipótesis:

1. Los estudiantes de primer grado que han recibido la instrucción de lectura con las estrategias pictofónicas tendrán un mejor reconocimiento de vocales a corto plazo que los estudiantes que han recibido la instrucción con el método ecléctico.

2. Los estudiantes de primer grado que han recibido la instrucción de lectura con las estrategias pictofónicas tendrán un mejor reconocimiento de sílabas a corto plazo que los estudiantes que han recibido la instrucción con el método ecléctico.

3. Los estudiantes de primer grado que han recibido la instrucción de lectura con las estrategias pictofónicas tendrán una mejor lectura de palabras a corto plazo que los estudiantes que han recibido la instrucción con el método ecléctico.

4. Los estudiantes de primer grado que han recibido la instrucción de lectura con las estrategias pictofónicas realizarán mejor las tareas de segmentación fonética a corto plazo que los estudiantes que han recibido la instrucción con el método ecléctico.

\section{Metodología}

Como este estudio pretende comprobar la adquisición de una mejor decodificación de las sílabas y palabras, mediante el dominio de las reglas de correspondencia grafema-fonema, por parte de estudiantes instruidos con dos métodos diferentes, se puede afirmar que es una investigación aplicada.

Al respecto, León y Montero (2003) afirman que el propósito fundamental de este tipo de estudio es probar que algo funciona, su objetivo es: "per se, que aparezca la mejoría, que sea importante y que permanezca después de la retirada del tratamiento" (p. 328).

Como era imposible conseguir, en asignación aleatoria, los grados de semejanza similares entre los 333 estudiantes participantes, se optó por un diseño pre-post con grupo de cuasi control, porque pretende establecer el impacto del tratamiento comparando una medida anterior y otra posterior a éste, tomada en los grupos, de los cuales al grupo experimental se le aplica el tratamiento y al de cuasi control no, refiriéndose el prefijo "cuasi" a que no cumple las condiciones de los controles experimentales. 


\section{Participantes}

Costa Rica, en la administración educativa, está dividida en 23 regiones de las cuales, Cartago, según el Departamento de Estadística del MEP, es la tercera con mayor número de estudiantes en primer grado, con un total de $6.294(8,1 \%)$, de los 77.625 matriculados en el período lectivo 2010, por lo que la hace una zona suficientemente representativa de la población estudiantil costarricense.

Para este estudio, se seleccionaron seis escuelas públicas pertenecientes al Núcleo Uno del Circuito 05 de la Región Educativa de Cartago, que por su cercanía geográfica, comparten características socioeconómicas y culturales semejantes, permitiendo así la equivalencia de la población estudiantil de las tres escuelas que integran el grupo control en relación con las tres del grupo experimental.

La distribución de los docentes y los estudiantes, en los grupos escolares, fue establecida por cada institución a partir de la matrícula que realizaron en el mes de diciembre del 2009, lo que sirvió como procedimiento de control de variables extrañas, pues el entorno educativo hace que: "no haya más remedio que asignar a las condiciones experimentales 'grupos formados antes de la investigación' en vez de asignar a los participantes uno a uno" (León y Montero, 2003, p. 219).

Para la equivalencia, en número de estudiantes, entre los grupos control y experimental, se consideró la cantidad de niños y niñas de cada institución. La asignación de cuál grupo aplicaría las estrategias pictofónicas como tratamiento y cuál el método ecléctico como programa alternativo fue dado al azar.

\section{Estudiantes}

Se consideraron los 333 estudiantes matriculados en febrero del 2010 en los seis centros educativos, es decir, 5,29\% de la población de primer grado de Educación General Básica de la Región Educativa de Cartago, distribuidos en siete secciones por grupo de estudio.

Al tomar las medidas del pretest en febrero de 2010, no se encontraron diferencias significativas entre los grupos en el conocimiento medio de las vocales $\left(t_{331}=1{ }^{\prime} 521 ; p=0 ` 129\right)$, no obstante, sí se observó un continuo que va desde los estudiantes que no conocían ninguna vocal $(27,3 \%)$ hasta algunos pocos que identificaban más de 100 sílabas (3\%).

Como se pretendía comprobar la eficacia de un método en la enseñanza de la lectura, se ajustó el criterio de selección (análisis de bondad) de los estudiantes, para la homogeneidad de 
los grupos, a sólo aquellos que reconocían menos de cinco vocales, comprobándose con la prueba T-Student, un nivel de significancia mayor ( $\left.t_{214}=1 ` 369 ; p=0 ` 172\right)$.

Al descartar a los estudiantes que tenían conocimientos más avanzados en lectura, adquiridos, posiblemente, en el contexto familiar, se logró que todos los estudiantes participantes en el estudio tuvieran un conocimiento incompleto de la regla de correspondencia grafema-fonema en las vocales, por lo que la muestra definitiva se estableció en 216 estudiantes, el 3,43\% de la población de primer grado de la Región Educativa de Cartago, 98 en el grupo experimental y 118 en el grupo cuasi control, 107 mujeres, 109 hombres, de entre 6 y 7 años de edad.

\section{Docentes}

Es importante destacar también algunos datos relevantes sobre las 13 docentes que tienen a cargo las 14 secciones de primer grado, ya que permite mostrar la forma en que se ha tratado de controlar el efecto del docente como variable oculta en esta investigación.

A partir del historial profesional, que se obtuvo mediante un cuestionario de preguntas cerradas y validado por cinco docentes de primaria, se puede decir que las docentes del grupo control cuentan con mayor experiencia laboral, ya que tienen mayor edad ( ${ }^{x}=45$ ); el $57,1 \%$ ha trabajado por más de 16 años en educación; el 85,6\% ha impartido primer grado anteriormente, y el $71,4 \%$ usó el método ecléctico en la enseñanza de la lectura. Las docentes de ambos grupos muestran un nivel académico similar, pero cabe decir que el grupo control tiene una docente más, con nivel de bachillerato, en relación con el grupo experimental, pues en una de las escuelas (E3), hay una única docente que tiene a cargo las dos secciones de primero que participan en el proyecto.

\section{Procedimiento}

Al ser una investigación cuasi experimental, que involucra un seguimiento en el proceso de enseñanza de la lectura en seis escuelas públicas del Circuito 05 de la Región Educativa de Cartago, fue indispensable contar con el apoyo del Supervisor Escolar de esta zona, ya que, como representante del Ministerio de Educación Pública, debía autorizar la ejecución del proyecto, además del apoyo de los directores de los centros educativos y la anuencia de las docentes a participar en la investigación. 
La primera semana de febrero de 2010, previa al inicio del curso lectivo, se les solicitó a las docentes participantes iniciar la enseñanza de la lectura a partir del 22 de febrero, con el propósito de registrar en el pretest, aplicado entre el 15 y el 19 de febrero, los conocimientos previos de lectura de cada uno de los estudiantes que tienen a su cargo.

Durante el pretest, en el horario escolar de los estudiantes de primer grado (lunes, miércoles y viernes de 12:30 p.m. A 5:40 p.m.; martes y jueves de 7:00 a.m. a 12:10 p.m.), una institución cada día, en el aula más pequeña que tuviera esa escuela, se midió, en forma individual, el conocimiento de las cinco vocales de cada uno de los estudiantes, con las tarjetas descritas en los instrumentos. Los datos se registraron, en forma individual, en el denominado registro silábico.

El período de instrucción se inició el 22 de febrero de 2010 en las seis escuelas participantes. En el transcurso de las 17 semanas que implicó el proceso inicial de enseñanza de la lectura con las dos estrategias en estudio, las docentes del grupo experimental siguieron la sistematización de las estrategias pictofónicas (Carpio, 2000), y las del grupo cuasi control ejecutaron los pasos establecidos en El método ecléctico (N. de Chacón, 1994), con la diferencia en la cantidad de sílabas por enseñar, pues este método introduce una sílaba con /a/ por cada cartel de presentación, después de los primeros seis carteles tienen seis sílabas: pa, la, ma, da, sa, ta, y la interiorización de la vocal a; procedimiento considerado por las docentes como muy lento, por lo que decidieron introducir en el período de aprestamiento, las cinco vocales para extraer después, con cada cartel, la serie silábica completa; de esta forma, con los mismos seis carteles se tendría: pa-pe-pi-po-pu, la-le-li-lo-lu, etc, es decir, 30 sílabas en lugar de seis.

Esta modificación se estableció como estrategia innovadora entre las docentes, para cumplir el requisito metodológico de que: "el control necesita recibir un programa placebo, dedicar el mismo tiempo que el experimental a una tarea distractora, asegurarse que no recibe la influencia de una variable extraña" (León y Montero, 2003, p. 332).

A pesar de que es necesaria la descripción detallada de la metodología empleada en las 17 semanas de instrucción con cada una de las estrategias de lectura en comparación, el espacio de este informe es insufiente, por lo que se sugiere leer el texto El método ecléctico ( $\mathrm{N}$. de Chacón, 1994) y la sistematización de las estrategias pictofónicas (Carpio, 2000); sin embargo, se describen aquí los procesos básicos que realizaron las docentes durante los 80 minutos diarios que corresponde a la clase de español en primer grado. 
El método ecléctico está dividido en cinco etapas, descritas en la introducción, de las cuales las dos primeras, Aprestamiento e Iniciación, son las que se refieren a la enseñanza de la lectura. En la Etapa de Aprestamiento se desarrollan las destrezas básicas en las áreas cognoscitiva (percepción y discriminación visual, auditiva, táctil, gustativa y desarrollo del lenguaje), socioafectiva (integración del medio social, afirmación del yo, independencia, formación y expresión de sentimientos) y motriz (coordinación gruesa y coordinación fina).

Aunque le corresponde al Nivel de Preescolar trabajar estas destrezas, el método establece el primer trimestre del curso lectivo al desarrollo de estas áreas, y así se estipula también en el primer objetivo del Programa de Estudios de Español (2005), por lo que las docentes del grupo control decidieron trabajar esas áreas entre febrero y abril.

La Etapa de Iniciación parte de la presentación de oraciones significativas para los estudiantes, organizadas en pequeños textos que giran alrededor de un tema central relacionado con asuntos de interés y vivencias, y que contienen, además, un elemento común (EC) muy sugestivo. Ese elemento propone diferentes tipos de carteles (de experiencia, preparatorios, nombres propios, rótulo y medio ambiente, lámina y palabra) como recurso importante para la enseñanza de la lectura.

El primero de los carteles fue presentado en la tercera semana de abril de 2010, después de casi dos meses de aprestamiento. Con éste, se realizaron los tres procesos de análisis que recomienda el método.

El primero, la separación del texto en las oraciones que los constituyen para propiciar su reconocimiento, inicialmente con base en la forma general de cada oración clave o guía de configuración y para propiciar la determinación del elemento común (EC) o palabra clave. El segundo, la descomposición de esas oraciones en las palabras que los constituyen, con el propósito de que los estudiantes, al contar con palabras aisladas, formen nuevas oraciones y resuelvan diversos ejercicios de clave de contexto. El tercero corresponde al silábico para generar, a partir de la palabra clave o elemento común, la serie silábica a estudiar.

Para cada uno de los once carteles preparatorios que se proponen para primer grado, se llevan a cabo los tres tipos de análisis, generándose a partir de cada uno de ellos el aprendizaje de una o varias series silábicas directas (CV), según la cantidad de palabras claves que se tomen del texto. Los demás tipos de sílabas (inversas, mixtas y consonánticas) corresponde su enseñanza al segundo grado de primaria. Al finalizar la semana 17, las docentes del grupo 
control habían presentado los dos primeros carteles preparatorios, de los que extrajeron las sílabas directas con la letra I y la letra $\boldsymbol{t}$.

Por su parte, las estrategias pictofónicas están organizadas en etapas y fases, no sucesivas sino simultáneas, que permiten la interacción constante entre el desarrollo del sistema ortográfico y las representaciones fonológicas, tal y como se ve a continuación.

La Etapa Perceptual estimula la lectura logográfica de carteles del ambiente, con el objetivo de estimular el reconocimiento y almacenamiento de palabras del contexto (ABIERTO, CERRADO, HALE, EMPUJE, PELIGRO), la conciencia fonológica, en las áreas léxica y silábica; y la correspondencia grafofónica de las vocales por medio del pictograma y la palabra clave.

La Etapa de Decodificación dio inicio la primera semana de abril. Para adquirir esta destreza se proponen tres fases: la conciencia fonémica, para la introducción de las letras consonánticas y sus correspondientes sonidos; la fusión silábica para enseñar las reglas de correspondencia grafema-fonema que permite la decodificación de las diferentes sílabas según la posición de los grafemas; y la lectura de palabras, con ejercicios constantes de lectura y dictado, para estimular la conciencia fonológica. En la tercera semana de junio, las docentes del grupo experimental habían presentado cuatro grafemas $m-s-I-p$, es decir, 20 sílabas directas y 10 inversas, aunque cabe mencionar que a pesar de que la metodología sugiere que se presente directa e inversa simultáneamente, las docentes, por inseguridad, habían solicitado introducir sólo las sílabas directas.

La Etapa de Comprensión inició desde el mes de abril, ya que se guía a los estudiantes en la comprensión lectora desde la primera serie silábica, es decir, ma-me-mi-mo-mu, con oraciones sencillas formadas con las sílabas conocidas, como Memo ama a Ema. Para el desarrollo del procesamiento semántico, se acompañan las oraciones con ilustraciones que estimulan la construcción de representaciones mentales del contenido. El proceso sintáctico que se estimula en la Etapa de Redacción, se introdujo en el mes de junio, al contar los estudiantes con suficiente vocabulario para estructurar oraciones en el esquema de sujetoverbo-predicado, en clave de color.

La aplicación del postest en los grupos de estudio se realizó de la misma forma en que se organizó el pretest, es decir, en el horario de los estudiantes, en un aula pequeña y en forma individualizada; pero en lugar de una escuela por día, se realizaron dos visitas por institución, ya que el número de pruebas que debía pasar a cada estudiante y el rendimiento que estaban 
presentando, especialmente los del grupo experimental, hizo que el proceso de medición se extendiera más de lo esperado. En esta fase se incluyó la grabación de voz de todos los estudiantes y se realizó el registro conjunto de cinco estudiantes de cada sección con las docentes a cargo, para el control de fiabilidad de los datos obtenidos mediante los instrumentos que se describen a continuación.

\section{$\underline{\text { Instrumentos }}$}

Para medir el nivel de decodificación alcanzado por los estudiantes del grupo cuasi control y el experimental, en el primer semestre del curso lectivo 2010, que incluye el período comprendido entre febrero y junio del 2010, se utilizaron, durante el pretest, cinco tarjetas de $10 \mathrm{~cm} \times 10 \mathrm{~cm}$, cada una con la vocal escrita en letra imprenta del tipo Berlin Sans FB, número 150, para medir el reconocimiento de las cinco vocales en minúscula.

Tras las 17 semanas de instrucción, por el poco dominio de fonemas que se suponía tendrían los estudiantes, se midió el reconocimiento de las letras y las sílabas por medio del registro silábico del Diagnóstico Pedagógico de Lectura, Escritura y Aritmética, L.E.A (Murillo, Rojas, y Madrigal, 1999), que es una batería costarricense de pruebas informales que determina el nivel en que se encuentra el estudiante desde primero a sexto grado. La prueba de lectura evalúa el nombre y el sonido de las letras, el dominio de las sílabas, a partir del cual se seleccionan las subpruebas de palabras aisladas, palabras en contexto (lectura de texto) para determinar el nivel de lectura oral y silenciosa; y la subprueba de comprensión presenta preguntas relacionadas con esos textos.

Al considerarse, también, la adquisición de cierto nivel de lectura de palabras en los estudiantes, a partir del proceso de enseñanza con ambas estrategias, se analizaron los siguientes test de evaluación de lectura para determinar la conveniencia de su uso en esta primera etapa de la investigación: P.E.R.E.L, PROLEC y LEE.

La Prueba de Evaluación del Retraso en Lectura: P.E.R.E.L, (Maldonado, Sebastian y Soto, 1992), fue diseñada para aplicarse a estudiantes de primero a tercero de primaria, para la identificación de dificultades significativas de aprendizaje de la lectura y evaluación específica del grado de retraso en lectura, que consta de una lista de 100 palabras, graduadas en orden creciente de dificultad, que el estudiante debe leer sucesivamente. 
La Prueba de Evaluación de Procesos Lectores: PROLEC (Cuetos, Rodríguez y Ruanos, 2002), evalúa la capacidad lectora y los procesos que intervienen en la lectura en estudiantes de 6 a 9 años y en estudiantes mayores con problemas de lectura. Está formada por 10 pruebas que se agrupan en cuatro bloques: identificación de letras (nombre o sonido de las letras e igual-diferente en palabras y pseudopalabras), procesos léxicos (decisión léxica, lectura de palabras y lectura de pseudopalabras), procesos sintácticos (estructuras gramaticales y signos de puntuación) y procesos semánticos (comprensión de oraciones y textos).

El Test de lectura y escritura en español: LEE (Defior, Fonseca, Gottheil, Aldrey, Jiménez, Pujals, Rosa y Dolores, 2006), es una batería de evaluación que consta de pruebas de lectura de palabras, lectura de pseudopalabras, comprensión de palabras y frases (frases, familia de palabras, preguntas, completar), prosodia, comprensión de textos, escritura de palabras y escritura de pseudopalabras; además de dos subpruebas complementarias de segmentación fonémica y lectura de letras.

Por la cantidad de las palabras que se incluyen en las subpruebas de lectura en los tres test descritos, se decidió elaborar un registro común para todas ellas con un formato que resultara de mayor facilidad para la recogida de datos y más reducida para la presentación a los estudiantes, quedando una lista de tres columnas con las primeras 10 palabras de cada prueba: a la izquierda las palabras del test P.E.R.E.L, en el centro las del test PROLEC, y a la derecha las del LEE.

Para el análisis de los resultados de este registro, se consideraron las normas de puntuación y corrección que establece la prueba P.E.R.E.L, con las siguiente adaptación: dos puntos por cada palabra leída correctamente, un punto por cada palabra leída correctamente, pero en forma silabeada o vacilante, y cero puntos por cada palabra no leída o leída incorrectamente. Este criterio se fundamenta en la caracterización del silabeo como el error más frecuente en el dominio de la lectura (Maldonado, Sebastián y Soto, 1992).

Con la aplicación de estos instrumentos, más la prueba complementaria de segmentación fonémica del test LEE, se obtuvieron los resultados que se presentan a continuación.

\section{Resultados y su análisis}

Como se ha señalado anteriormente, el principal objetivo de la investigación es comprobar experimentalmente la adquisición, a corto plazo, de una mejor decodificación de sílabas y 
palabras, mediante el dominio de las reglas de correspondencia grafema-fonema, por parte de los estudiantes de primer grado instruidos con las estrategias pictofónicas en comparación con el método ecléctico.

Aunque el diseño general de la investigación incluye medidas pre y postest, es necesario señalar que en casi todas las variables dependientes a nivel de pretest, el resultado es cero, en ambos grupos; por esa razón, para el contraste de las hipótesis, en lugar de un ANOVA se utilizó un contraste de medias, para analizar si la mejora del grupo experimental es significativamente mejor que el grupo control. Se utilizó del paquete de aplicaciones estadísticas SPSS 17.0, la prueba de contraste T-Student, con un intervalo de confianza del 95\%, para establecer las diferencias entre ambas estrategias de aprendizaje, a partir del análisis de los datos obtenidos para cada una de las hipótesis planteadas: reconocimiento de las vocales, decodificación de sílabas, lectura de palabras y segmentación fonética. Se utilizaron los diagramas de cajas para ilustrar los resultados de cada una de las escuelas participantes.

\section{Primer análisis: Vocales}

Como en Costa Rica la enseñanza de la lectura se inicia en primer grado, se consideró suficiente el registro del conocimiento de sólo las vocales por parte de los 333 estudiantes participantes en la investigación, como medida para el pretest al inicio del curso lectivo.

Tabla No. 1

Porcentaje de reconocimiento de vocales por escuela en el pretest

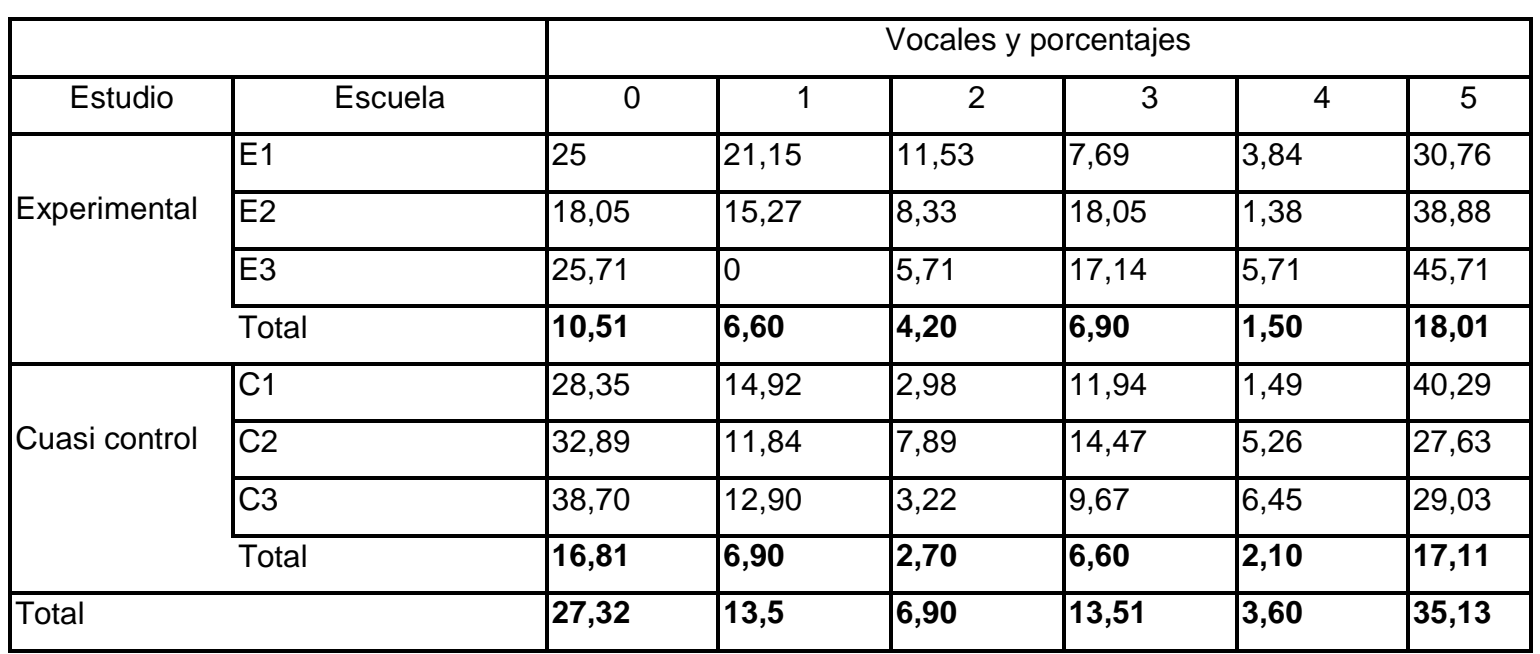


La Tabla No. 1 muestra que el $27,32 \%$ de los estudiantes no reconocieron vocales, de los cuales $10,51 \%$ pertenecen al grupo experimental y $16,81 \%$ del grupo cuasi control. Una sola vocal fue reconocida por el $13,51 \%$ del total de la muestra, correspondiendo el $6,60 \%$ al grupo experimental y $6,90 \%$ al cuasi control. El 4,2\% de los estudiantes instruidos con las estrategias pictofónicas reconocieron dos vocales, y del método ecléctico, leyeron esa cantidad, el 2,70\%. El porcentaje de reconocimiento de tres vocales es muy parecido en ambos grupos, con 6,90\% el experimental y $6,60 \%$ el cuasi control, para un total de $13,51 \%$. Es muy bajo el porcentaje de identificación de cuatro vocales, pues sólo un $3,60 \%$ de los 333 estudiantes valorados, lo logra realizar. Caso contrario sucede con el reconocimiento de las cinco vocales, donde el $35,13 \%$ las reconocen, $18,01 \%$ del grupo experimental y $17,11 \%$ del grupo cuasi control.

A pesar de no encontrarse diferencias significativas en la media de las vocales entre las escuelas que conforman el grupo cuasi control y las que corresponden al grupo experimental ( $\left.t_{331}=1 ` 521 ; p=0 ` 129\right)$, se observó que existían, como era de prever, un mayor conocimiento de las vocales entre algunos estudiantes, e incluso, se detectó la lectura incipiente de palabras y de textos en algunos de ellos, que obviamente habían aprendido estas correspondencias grafemas-fonemas al margen de la escuela, debido al interés de los padres o de otras personas significativas.

Para garantizar que el contraste de las hipótesis no fuera influenciado por este factor, se decidió no incluir en el estudio a los estudiantes que reconocían las cinco vocales, para así contar con una muestra que no tuviera ningún nivel silábico ni lectura de palabras, y contrastar objetivamente ambas estrategias con grupos homogéneos, como se observa en la Figura No. 1, que refleja el conocimiento medio las vocales antes y después de haber recibido la instrucción. 
Figura No. 1

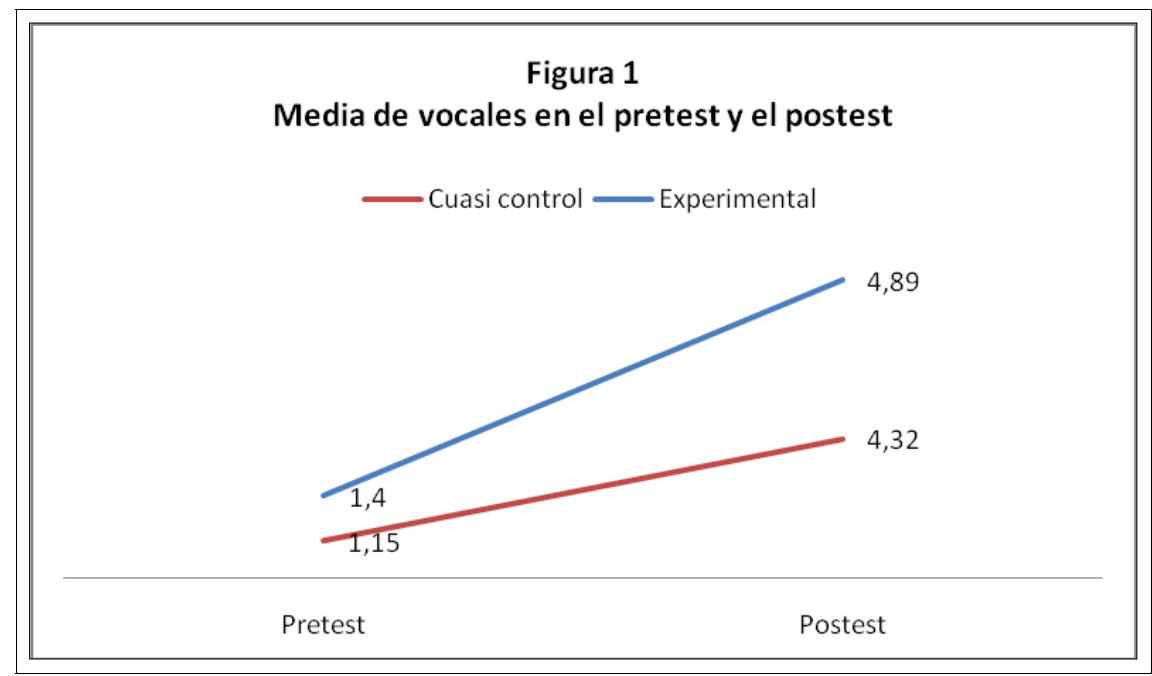

Con ese criterio general, de excluir a los estudiantes con un conocimiento incipiente de la lectura operativizado en la identificación de las cinco vocales, la muestra definitiva quedó compuesta por 216 estudiantes. Al aplicar la prueba de contraste, se determinó que no habían diferencias significativas entre el grupo experimental (E1, E2, E3) y el grupo cuasi control (C1, $\mathrm{C} 2, \mathrm{C} 3)$ en el reconocimiento de vocales $\left(t_{214}=1^{\prime} 369 ; p=0 ` 172\right)$.

Durante las semanas de intervención, hubo pérdida de sujetos, pues 22 estudiantes se trasladaron de escuela, 11 del grupo experimental y 11 del grupo cuasi control, por eso la muestra quedó integrada por 194 estudiantes, 87 en el primero y 107 en el segundo, a quienes se les aplicó el postest en las dos últimas semanas del mes de junio.

En los días que se aplicaron las pruebas, las docentes participantes no introdujeron fonemas ni sílabas nuevas, para lograr el mismo nivel de instrucción entre las secciones que conforman el grupo cuasi control y el experimental. Los resultados del reconocimiento de las vocales de los 194 estudiantes en el postest se muestran en la Figura No. 2. 
Figura No. 2

Diagrama de vocales en el postest

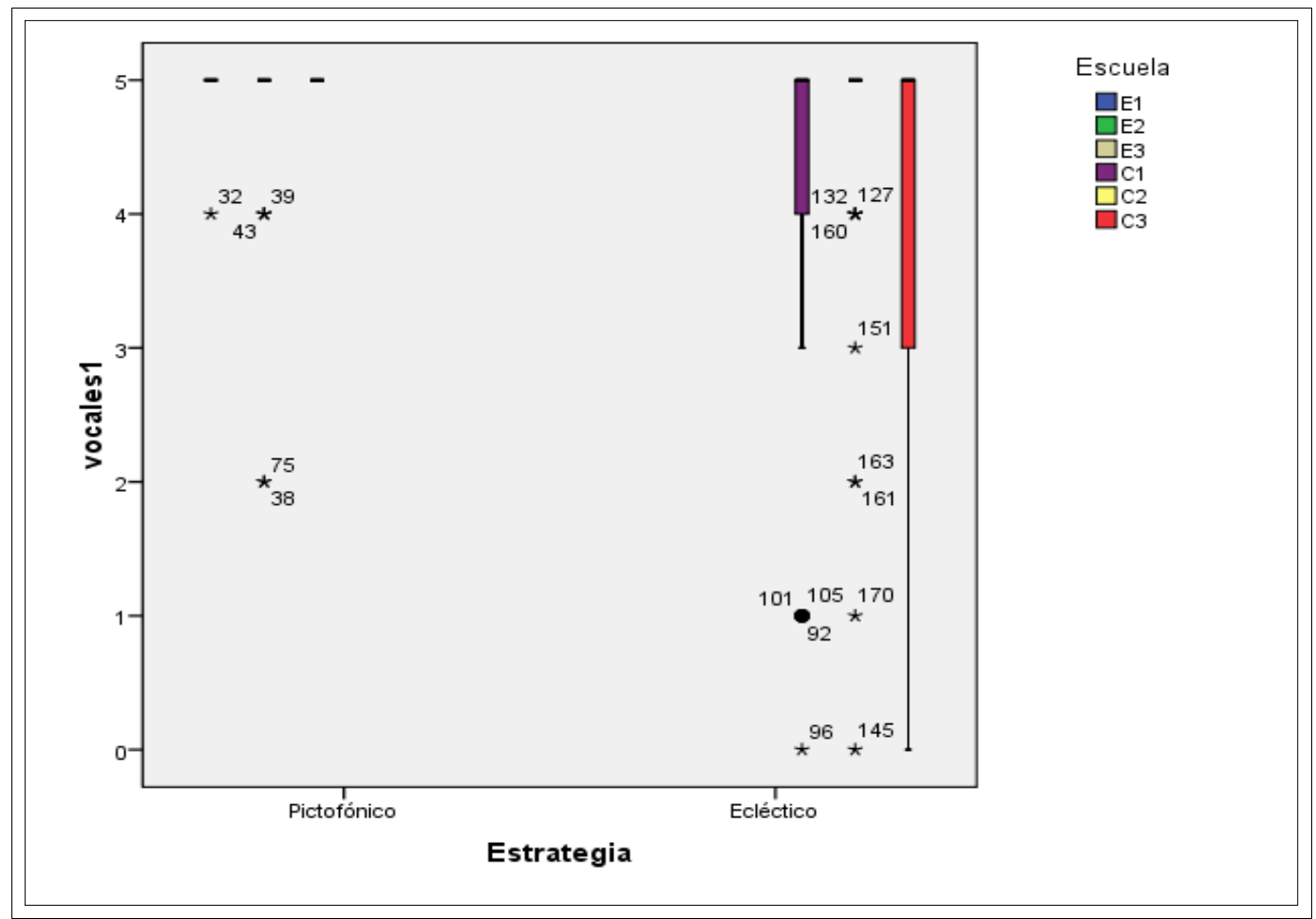

En este diagrama se puede observar que casi todos los estudiantes que están recibiendo la instrucción con las estrategias pictofónicas (grupo experimental), reconocen todas las vocales, a excepción de cinco estudiantes (18\%) que se muestran como casos extremos $\left(^{*}\right)$ al reconocer menos de las cinco vocales, cuatro de la escuela E2 y uno de la escuela E1. El 100\% de los estudiantes de la escuela E3 domina las cinco vocales.

En el análisis de dispersión del grupo cuasi control, se observa asimetría negativa en dos de ellas, $\mathrm{C} 1$ y $\mathrm{C} 3$, porque el $50 \%$ de sus estudiantes está por debajo de la media de cinco vocales que reconoce el resto de sus compañeros; la segunda escuela presentó la mayor dispersión entre los estudiantes que reconocen entre cero y cuatro vocales. El 90,19\% de los estudiantes de la escuela C2 identifican todas las vocales, con excepción de nueve casos extremos que reconocen entre cero y cuatro vocales.

Al aplicar la prueba de contraste entre el grupo experimental y el cuasi control, en el reconocimiento general de vocales, se encontraron diferencias estadísticamente significativas $\left(t_{192}=3^{\prime} 793 ; p=0 ` 000\right)$ a favor del primero, lo que permite verificar la primera hipótesis de esta 
investigación, dado que existe un mejor reconocimiento, a corto plazo, de las vocales por parte de los estudiantes instruidos con las estrategias pictofónicas.

\section{Segundo análisis: Sílabas}

En este apartado es necesario tomar en cuenta que el castellano tiene distintas estructuras silábicas organizadas por grados de dificultad, lo que genera importantes diferencias entre los estudiantes a la hora de leer. Es por eso necesario hacer un análisis del total de sílabas, y otro de los tipos de sílabas, considerando la clasificación secuencial que se utiliza en el contexto educativo costarricense (García, R. de Chacón y Guzmán 1996):

1.Sílaba directa. Corresponde al grupo silábico de consonante + vocal (CV). Aquí se incluyen también las sílabas gue, gui, güe, güi, que, qui.

2.Sílaba inversa. Es el conjunto silábico de vocal + consonante (VC).

3. Sílaba mixta. Formada por el grupo consonante + vocal + consonante (CVC).

4. Sílaba consonántica. Incluye la secuencia consonante + consonante + vocal (CCV).

De estas sílabas, se destaca el rendimiento de los estudiantes en las sílabas directas, por grupo de estudio (experimental y cuasi control) y por escuela en un diagrama de cajas, debido a que en ambas estrategias de aprendizaje, la intervención durante el período previo al postest incluyó la enseñanza formal y estructurada de sólo ese tipo de sílaba. De las otras sílabas (inversa, mixta y consonántica) se muestra el contraste entre las medias de los estudiantes, por las cantidades tan bajas que lograron decodificar, pero esos datos serán considerados, junto con los de las sílabas directas, en el análisis que se hará luego del total de sílabas decodificadas por los estudiantes participantes. 
Figura No. 3

Diagrama de sílabas directas en el postest

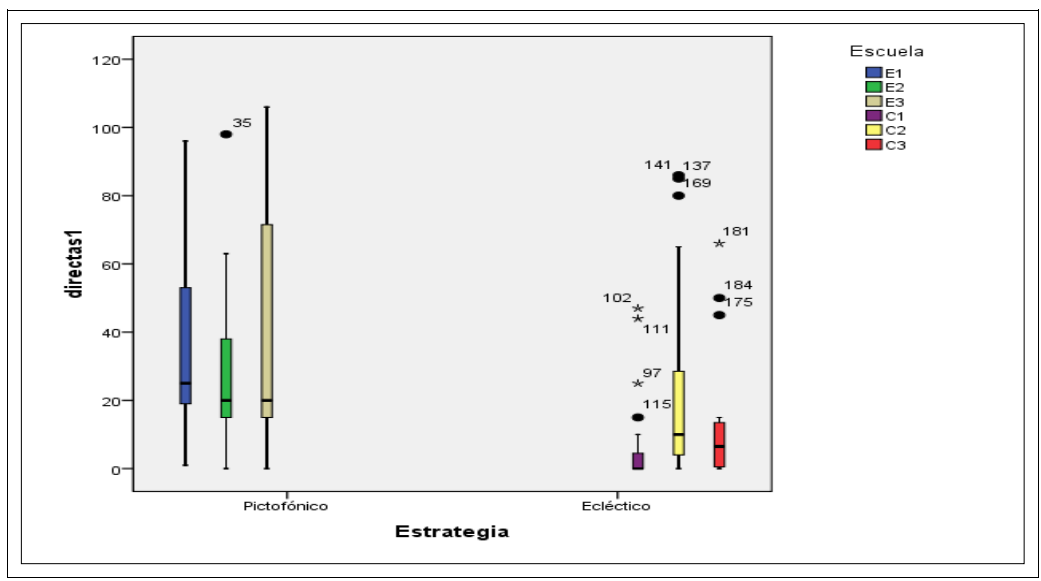

En la Figura No. 3 se observa que los estudiantes del grupo experimental tienen mayor reconocimiento de sílabas directas que los del grupo cuasi control, pues sus medianas son superiores, hay mayor dispersión en la cantidad de sílabas que reconoce el $50 \%$ de los estudiantes, en una distribución asimétrica positiva, donde la mitad de esos estudiantes decodificó más de 20 sílabas directas. La escuela E3 es la que presenta la mayor cantidad de sílabas directas reconocidas, con 106 de las 213 correspondientes, y la que tiene el único caso atípico, con una decodificación de 98 sílabas directas.

La mediana entre las escuelas que aplican el método ecléctico no supera las 10 sílabas reconocidas, llegando inclusive a cero en la escuela $\mathrm{C} 1$, donde se registra el menor número de sílabas directas, con un máximo de 47. Las tres instituciones presentan una dispersión menor, pero con una asimetría positiva, se presentan cuatro casos extremos y seis atípicos, distribuidos en las tres escuelas; la menor cantidad de sílabas directas decodificadas es cero, la cantidad más alta fue de 86 , en la escuela $\mathrm{C2}$.

Tomando en cuenta los datos anteriores y al hacer una comparación de medias de reconocimiento de sílabas directas entre los estudiantes del grupo experimental ( ${ }^{x}=30,17$ ) y los del grupo cuasi control $\left({ }^{x}=12,92\right)$, se confirma que hay diferencias significativas entre ambos grupos $\left(t_{192}=5^{\prime} 333 ; p=0{ }^{`} 000\right)$, por lo que se puede decir que los estudiantes que están 
recibiendo instrucción con las estrategias pictofónicas decodifican mejor las sílabas directas que los del método ecléctico.

Como se mencionó, lo relevante en los otros tipos de sílabas, es la media que se obtiene al considerarlas en conjunto, es decir, partiendo de un total de 95 sílabas (20 inversas, 10 mixtas y 65 consonánticas), porque la diferencia que se establece entre el grupo experimental y el cuasi control, es altamente significativa $\left(t_{192}=5^{\prime} 945 ; p=0^{`} 000\right)$. Considerando que en ninguno de los grupos han sido enseñadas formalmente estas sílabas, se puede decir que los estudiantes que están aprendiendo con las estrategias pictofónicas logran generalizar, a corto plazo, hacia otros tipos de sílabas, donde el grupo experimental tiene una media $\left({ }^{x}=10,29\right)$ más alta que el grupo cuasi control $\left({ }^{x}=0,9\right)$.

Si se unen las sílabas inversa, mixta y consonántica con las directas, se obtiene un total de 218 sílabas, dato importante de contrastar, porque corresponde a la tercera hipótesis de la investigación. Mediante la T Student se obtuvo que existen diferencias significativas $\left(t_{192}=5^{\prime} 979\right.$; $\left.\mathrm{p}=00^{`} 000\right)$ entre el grupo experimental $\left({ }^{x}=40,46\right)$ y el grupo cuasi control $\left({ }^{x}=13,81\right)$, de manera que se puede afirmar que los estudiantes que están aprendiendo a leer con las estrategias pictofónicas tienen mejor reconocimiento de sílabas a corto plazo que los otros estudiantes, tal y como se ve en la Figura No. 4.

Figura No. 4

Diagrama de decodificación de sílabas en el postest

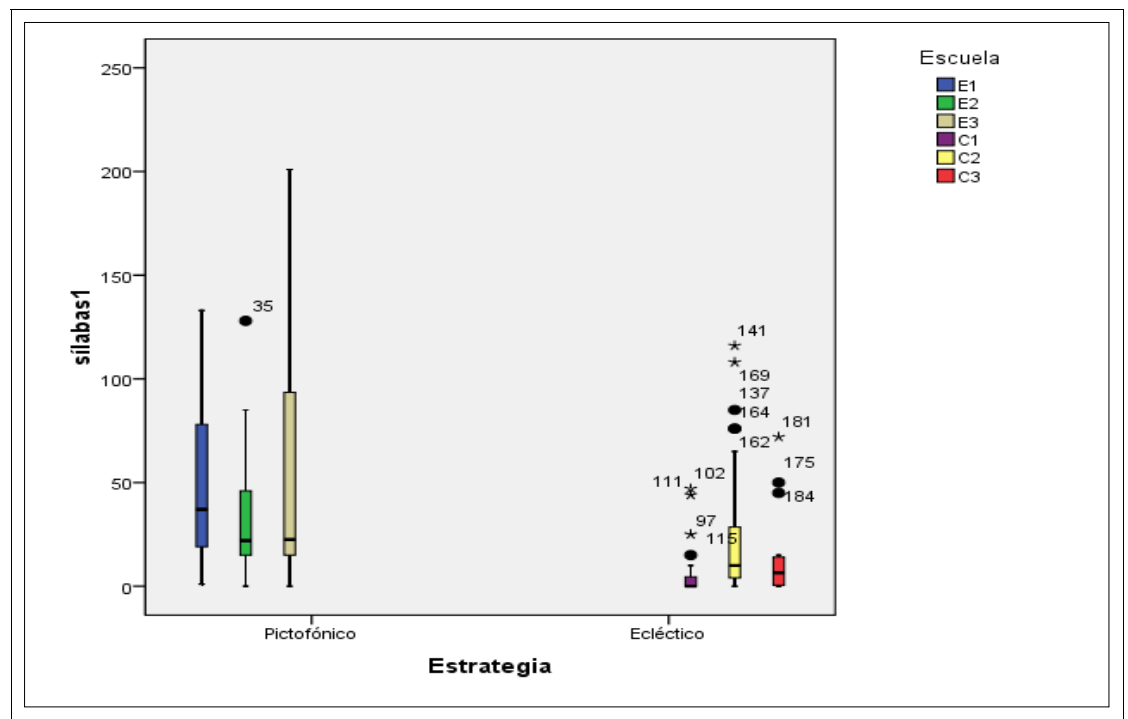


Los estudiantes del grupo experimental tienen mejor decodificación de sílabas que los del grupo cuasi control, porque sus medianas son superiores a 22 sílabas, hay mayor dispersión entre sus estudiantes, al mostrar los rectángulos una distribución asimétrica positiva, lo que indica mayor número de estudiantes que reconocen más de 22 sílabas, que es la mediana más baja. La escuela E3 presenta mayor cantidad de sílabas reconocidas, con un máximo de 201, seguida por la escuela E1 con 133 y la escuela E2 con 128 sílabas.

Ninguna de las escuelas del grupo cuasi control alcanza esos valores, el máximo se da en la escuela C2, con 116 sílabas que decodifica un caso extremo. En la escuela E2 es donde se presenta el único caso atípico en decodificación de sílabas, con 98 sílabas directas; mientras que son seis los casos atípicos y seis los extremos en el cuasi control.

Los estudiantes instruidos con el método ecléctico presentan medianas muy bajas en el reconocimiento de sílabas, la dispersión se concentra en valores muy por debajo de las medianas del grupo experimental, presentando el valor más alto la escuela C2 con una mediana de 10 sílabas, luego la escuela C3 con 6,50 sílabas y finalmente la escuela de $\mathrm{C} 1$, con una mediana de cero sílabas. La distribución de las escuelas de $\mathrm{C} 1$ y $\mathrm{C} 2$ es asimétrica positiva, aunque el rango en el número de sílabas que reconocen los estudiantes es muy bajo. La escuela C3 muestra una distribución más simétrica, aun con cantidades bajas de decodificación.

\section{Tercer análisis: Palabras}

Es importante considerar que en la lectura de palabras se presentan dos situaciones, la decodificación fluida- o lectura- y la decodificación no fluida, -descifrado- refiriéndose ésta última a la presencia de errores como el silabeo o la lectura vacilante (Maldonado, et al 1992, Defior et al, 2006).

Tomando en cuenta las normas de puntuación y corrección que establece la prueba P.E.R.E.L (Maldonado, Sebastian y Soto, 1992), se realizaron dos tipos de medidas para la variable palabras: Descifrado, que registra la decodificación no fluida de palabras; y Lectura, que recoge la decodificación fluida de palabras. Se muestra el valor de las medias de cada medida, por grupo de estudio, para destacar las diferencias.

La media de palabras descifradas por parte de los estudiantes del grupo experimental $\left({ }^{x}=2,24\right)$ es mayor que los del grupo cuasi control $\left({ }^{x}=0,28\right)$, según la prueba T-Student, 
produciéndose así diferencias significativas entre las medias observadas $\left(t_{192}=5^{`} 190 ; p=0 ` 000\right)$. A pesar de que la media de lectura de palabras con fluidez es bajo en ambos grupos, se presentan diferencias significativas entre ellas $\left(t_{192}=4^{\prime} 416 ; p=0 ` 000\right)$.

Al examinar en conjunto las dos medidas (descifrado y lectura) en la variable Palabras, se encuentra que las diferencias significativas entre los grupos de estudio aumenta $\left(t_{192}=5^{\prime} 361\right.$; $\mathrm{p}=0^{`} 000$ ) en una media de $x=1,94$ el grupo experimental y $x=0,78$ el grupo cuasi control. Sin embargo, los datos se vuelven más interesantes al analizar la cantidad de palabras leídas por tipo de estrategia y por escuela, como se muestra a continuación.

Figura No. 5

Diagrama de palabras decodificadas en el postest

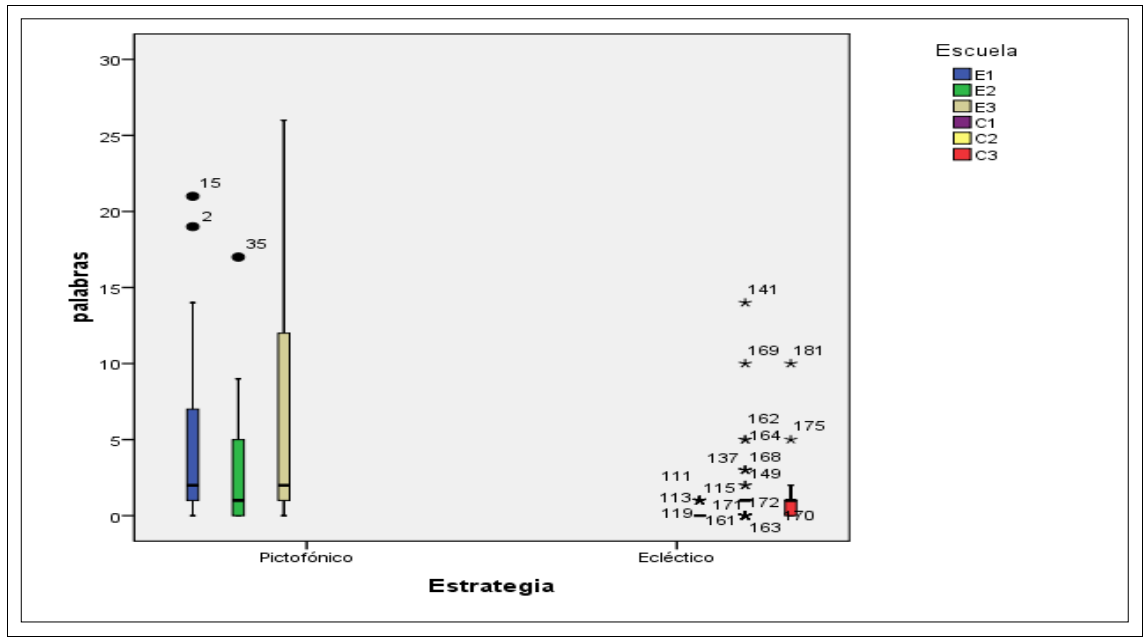

Los rectángulos de las tres escuelas del grupo experimental que se muestran en la figura 5 , evidencian mejor decodificación de palabras por parte de los estudiantes instruidos con las estrategias pictofónicas que los del grupo que están aprendiendo con el método ecléctico, donde sólo en la escuela C3 se ve una pequeña caja.

En el grupo control se observa el mayor número de casos extremos $\left({ }^{\star}\right)$, es decir, de estudiantes que han logrado reconocer más palabras que la mayoría del grupo, por alguna variable extraña, y no por el método en sí. Cuatro en la escuela C1, 11 en la escuela C2 y tres en la escuela C3. En el grupo control sólo se presentaron tres casos atípicos, dos en la escuela E1 y uno en la escuela E2. La escuela E3 no ha presentado casos extremos en ninguna variable. 
Se observa mayor dispersión en la cantidad de palabras decodificadas por los estudiantes del grupo experimental, con una distribución asimétrica positiva en las tres escuelas, logrando leer el $75 \%$ de los estudiantes de la escuela E1 hasta siete palabras, en la escuela E2 menos de cinco palabras, y en la escuela E3 hasta 12 palabras, de las 30 que incluía la prueba, siendo ésta última la que ha mostrado mejor rendimiento en todas las variables medidas.

A pesar del posible riesgo de existencia de un efecto suelo, debido al reducido número de palabras leídas en ambos grupos, parece posible descartarlo y verificar que los estudiantes de primer año que han recibido la instrucción de lectura con las estrategias pictofónicas tienen mejor lectura de palabras a corto plazo que los estudiantes que han recibido la instrucción con el método ecléctico. Es obvio que será necesario seguir contrastando esta hipótesis en periodos de instrucción más amplios, pero no por ello deja de ser relevante la existencia de estas diferencias.

\section{Cuarto análisis: Segmentación fonética}

La fuerte asociación existente entre la capacidad de segmentación fonética, evaluada mediante tareas metalingüísticas consistentes en quitar un sonido a una palabra (Liberman, 1973, Bryant y Bradley, 1983, Sebastián y Maldonado, 1986) nos permite utilizar esta medida para estimar el efecto de las dos estrategias de enseñanza.

En todo caso, conviene señalar que segmentar palabras en los sonidos que las constituyen no es una habilidad que se estimule, a pesar de que: "la relación entre fonemas y grafemas, es la base sobre la que se asienta nuestro sistema de escritura" (Barrio, 2007, p. 87).

Esta investigación explora el desarrollo de esta capacidad a partir del tipo de instrucción en la enseñanza de la lectura, después de 17 semanas de aplicación de ambas estrategias. No se encontraron diferencias significativas en la prueba de segmentación fonética de la prueba LEE en el pretest, pero sí en el postest $\left(t_{192}=4^{\prime} 242 ; p=0{ }^{\prime} 000\right)$ en la capacidad de los estudiantes de dividir las palabras en los sonidos que la conforman, por lo que se confirma la última de un mejor desempeño a corto plazo en la segmentación fonética por parte de los estudiantes del grupo experimental. 
Figura No. 6

Diagrama de segmentación fonética en el postest

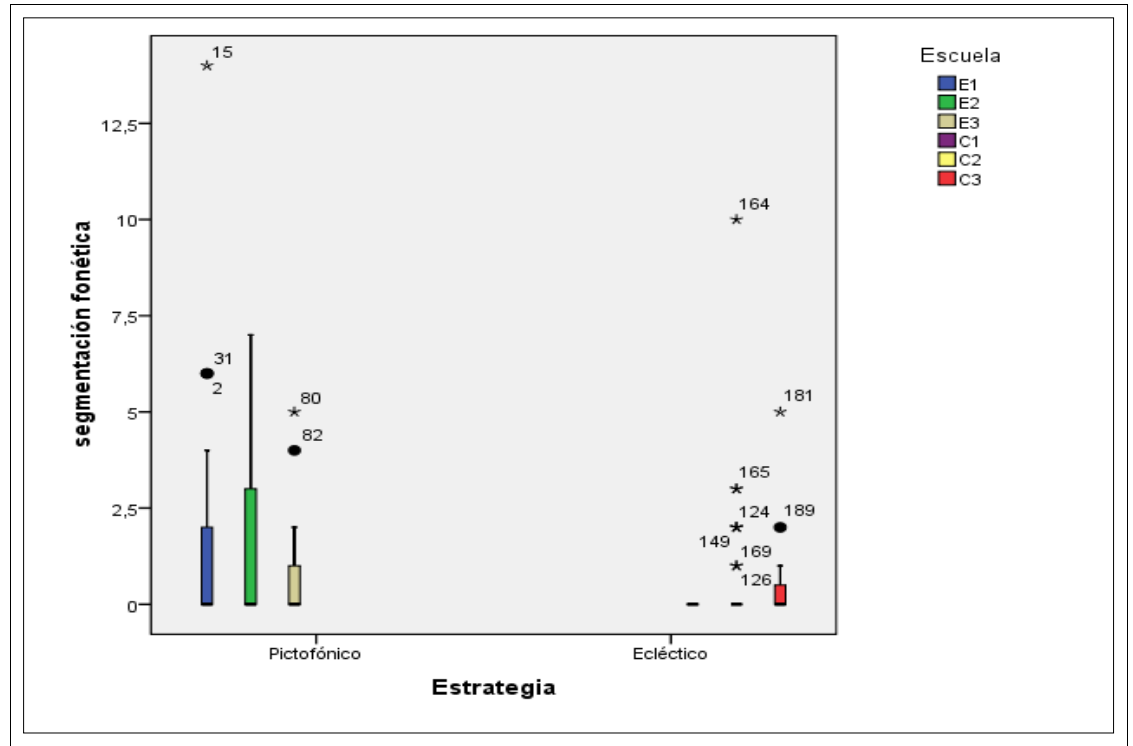

La información de la Figura No. 6 destaca que los estudiantes del grupo experimental logran, en mayor medida, la segmentación fonética, pues las cajas del diagrama presentan una simetría positiva de casi tres palabras segmentadas; mientras que los del grupo cuasi control, nuevamente sólo la escuela C3 alcanza una caja donde sólo el $25 \%$ de los estudiantes pudo aislar los sonidos de una palabra, el resto que lo logró hacer con dos o más palabras se consideran casos atípicos o extremos $\left({ }^{*}\right)$, que en total son nueve, siete de la escuela C2 y dos de la escuela C3. Ninguno de la escuela C1 pudo hacer la tarea.

De esta forma, al considerar los resultados en relación con las cinco hipótesis establecidas, se puede decir que existe evidencia suficiente para suponer que hay diferencias en el aprendizaje de la lectura entre los estudiantes instruidos con las estrategias pictofónicas y los estudiantes del método ecléctico.

\section{Conclusiones}

Los datos expuestos en este artículo corresponden al desempeño en decodificación de sílabas y palabras, mediante el dominio de las reglas de correspondencia grafema-fonema por parte de estudiantes de primer grado que han recibido instrucción con las estrategias pictofónicas en comparación con el método ecléctico. 
En el pretest se consideró innecesaria la medición de las 25 consonantes, ya que, de acuerdo con el Ministerio de Educación Pública, el proceso formal de la lectura inicia en primer grado, por lo que el conocimiento de este contenido habría sido generado fuera del contexto escolar, y no por la intervención.

En el postest se registró el conocimiento de las consonantes para analizar su adquisición a partir del proceso de enseñanza de la lectura. Como ninguno de los métodos enseña el abecedario hasta segundo grado, tal y como lo establece el programa de estudios de I Ciclo de Español, en la prueba de contraste no aparecen diferencias significativas entre las medias, de manera que la adquisición de éstas se da conforme aprenden los fonemas o conjuntos silábicos, según el método empleado.

En los análisis realizados al resto de variables, se encontró que los estudiantes que habían recibido el aprendizaje de la lectura por medio de la primera estrategia de aprendizaje (grupo experimental) durante las 17 semanas de instrucción, evidenciaron mejores resultados en relación con los que recibieron el aprendizaje de la lectura con el segundo método (grupo cuasi control), en:

1. El reconocimiento de las vocales, ya que el $93,1 \%$ de los estudiantes del grupo experimental logra identificar las cinco vocales, mientras que en el grupo cuasi control, es el $71 \%$ el que lo hace.

2. La decodificación de sílabas en cantidad y en tipo. El primero, porque en el grupo cuasi control la mediana más alta alcanzada entre las tres escuelas es de 10 sílabas; mientras que en el grupo experimental, las tres instituciones superaron la mediana de 22 sílabas. El segundo, porque varios estudiantes del grupo experimental lograron decodificar sílabas inversas, mixtas e incluso consonánticas, a diferencia del grupo cuasi control donde lo hicieron muy pocos casos.

3. La lectura de palabras, al lograr los estudiantes instruidos con las estrategias pictofónicas una mediana de lectura de entre una y dos palabras, en contraste con los del método ecléctico, en donde dos de las tres escuelas tuvieron medianas de cero.

4. La segmentación fonética, a pesar de que resultó una tarea difícil en los estudiantes participantes, la mayoría del grupo experimental logró aislar los sonidos de entre una y tres palabras, pero los del grupo control, sólo el $25 \%$ de estudiantes de una escuela alcanzó segmentar una palabra. 
En síntesis, se puede decir que los resultados obtenidos son los que se esperaban a partir de las hipótesis planteadas en esta investigación, ya que, efectivamente, los estudiantes instruidos con las estrategias pictofónicas reconocen mejor las vocales, sílabas y palabras, mediante el dominio de las reglas de correspondencia grafema-fonema, que es la clave que permite romper el código en la decodificación.

En el método ecléctico sucede lo contrario, a pesar de ser esencialmente silábico, la mayoría de los estudiantes han aprendido sólo las sílabas que las docentes les han enseñado, lo que hace suponer una metodología más pasiva, ya que los estudiantes esperan a que se les dé las sílabas y, al menos a corto plazo, no son capaces de usar estrategias generativas que les permitan leer nuevas palabras.

También se evidencia, no sólo una mejor decodificación por parte de los estudiantes del grupo experimental, sino un mejor desempeño en la segmentación fonética y mayor intento hacia la lectura de palabras; quizás porque las estrategias pictofónicas, al fundamentarse teóricamente en el modelo dual básico del desarrollo ortográfico de Seymour (2003), promueven el desarrollo de la conciencia fonética, uno de los procesos psicolingüísticos indispensables para el desarrollo de la lectura, que puede estar provocando un aprendizaje más activo que facilita la generalización hacia nuevas combinaciones silábicas.

La aplicación de un método no hace posible per se el aprendizaje de la lectura, sino que el conjunto de estrategias que éste incluya será lo que debe permitir construir los procesos psicolingüísticos que le permitan a los estudiantes analizar el lenguaje para adquirir el objetivo final que es la lectura, como se ilustra en este esquema.

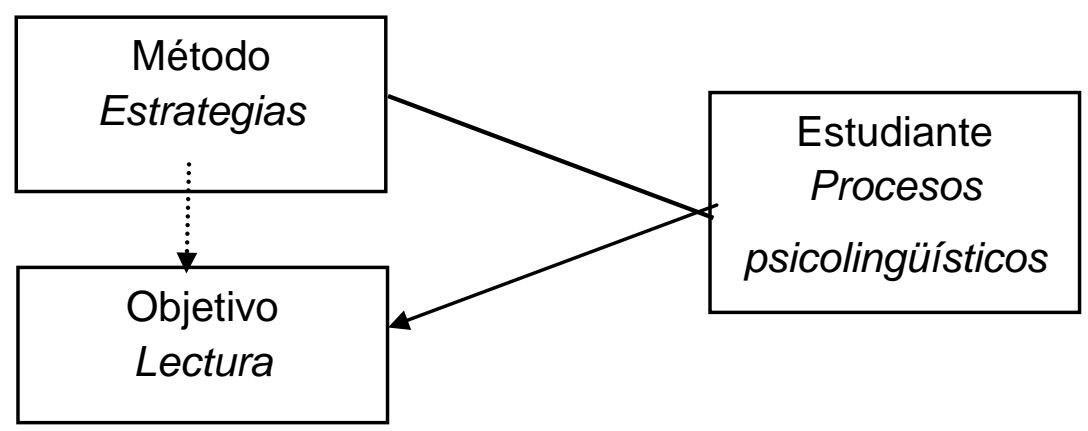

Respecto al papel de los docentes, al comparar la situación de las 13 maestras participantes, parece que las limitaciones que suelen presentar los estudios en contextos educativos se han podido controlar suficientemente en esta investigación, ya que, en el caso de 
las integrantes del grupo experimental, a pesar de que cuentan con menos años de experiencia laboral, son más jóvenes, no todas habían impartido primer grado y no conocían las estrategias pictofónicas, lograron que los estudiantes tuvieran mejores resultados en todas las variables medidas. Ellas iniciaron el proyecto con mucha ansiedad y recelo, que se manifestó hasta con la solicitud de una de las docentes, en mayo de 2010, de salir del proyecto, porque sus estudiantes no lograban fusionar los fonemas en sílabas.

En julio del mismo año se empezaron a ver los resultados del proceso, con la cantidad y tipo de sílabas que lograron leer, lo que las animó, inclusive, a enseñar las sílabas inversas y consonánticas, que habían decidido no introducir por temor, ya que se suelen enseñar en segundo grado.

Destacable es el caso de la docente de la escuela E3, quien es bachiller en Educación, nunca había impartido primer grado, tenía a cargo dos grupos, en un horario de 7:00 a.m. a 11:30 a.m. uno, y de 12:10 m.d. A 5:00 p.m. el otro, y cuyos estudiantes lograron los puntajes más altos en 3 de las 4 variables medidas.

Las docentes del grupo cuasi control, por su experiencia profesional, principalmente en la enseñanza de la lectura con el método ecléctico, se han mostrado, durante todo el año, más motivadas y productivas, pues en cada una de las reuniones elaboran material didáctico a partir de la serie silábica que corresponde al siguiente cartel de presentación. La docente de la escuela C3 diseñó un folleto con actividades que estimulan el reconocimiento de las sílabas en estudio y la lectura del vocabulario que surge a partir de esas convinaciones silábicas, que está siendo usado por el resto de las maestras de este grupo, como parte del trabajo en equipo que las ha caracterizado durante la investigación, y que se evidencia en el rendimiento mostrado por los estudiantes, pues corresponde a la cantidad de sílabas que deben reconocer de acuerdo con la metodología ecléctica.

Este estudio está programado para darle seguimiento a los estudiantes participantes durante el segundo año de escolarización, en el 2011, para constatar la existencia de diferencias significativas que permitan demostrar que las estrategias pictofónicas son efectivas en la enseñanza de la lectura inicial.

Los posteriores análisis en esta investigación pretenden establecer, principalmente, diferencias significativas que permitan demostrar que las estrategias pictofónicas son efectivas, y por tanto, pueden ser consideradas para un cambio curricular en la enseñanza de la lectura en Costa Rica, considerando que en este país 
se requiere fortalecer los procesos de investigación y aprovechar en mayor medida las experiencias innovadoras en la enseñanza de la Lengua, con el propósito de identificar prácticas efectivas que pueden ayudar a enriquecer tanto la formación de docentes como la formulación de programas de estudio en el Ministerio de Educación Pública. (Programa Estado de la Nación, 2008, p. 206)

Además, se pretende incluir, como nuevas líneas de investigación a partir de este estudio, el desarrollo de la conciencia fonológica en los estudiantes instruidos en uno y otro método; el análisis de errores en la lectura de los estudiantes; nivel de lectura alcanzado por los estudiantes repitentes en los dos grupos de estudio (experimental y cuasi control); la decodificación de las opiniones de los profesores sobre las experiencias de enseñanza con ambos métodos; entre otros ejes temáticos que puedan surgir en el transcurso de la investigación.

Es importante considerar también, a partir del informe del Estado de la Educación, una propuesta de diagnóstico para estudiantes de primer grado, desde la metodología empleada en esta investigación, pues, como se afirma en ese informe; "los docentes necesitan recursos adicionales que les ayuden a detectar e intervenir a tiempo en situaciones de niños y niñas que corran el riesgo de fracasar en el sistema educativo" (2011, p. 131).

\section{Referencias}

Alegría, Jesús, Carrillo, María, y Sánchez, Eloy. (2005). La Enseñanza de la lectura. Revista Investigación y Ciencia (34), 6-14.

Barrio, José. (2007). Los primeros pasos (por atajos y veredas) hacia la lengua escrita. En Ministerio de Educación y Ciencia. El desarrollo de la lectura y la escritura en la Educación Infantil y Primaria (pp. 67-93). España: Secretaría General Técnica.

Carpio, María de los Ángeles. (2000). Método Pictofónico: Una alternativa de aprendizaje de la lectura para la diversidad estudiantil. Cartago, Costa Rica: Imprenta Cartaginesa.

Carrillo, María y Marín, Javier. (1996). Desarrollo metafonológico y adquisición de la lectura: un programa de entrenamiento. Madrid: CIDE.

Chaves, Lupita. (2002). Los procesos iniciales de lectoescritura en el nivel inicial. Revista Actualidades Investigativas en Educación, 2 (1), 1-23. Recuperado el 30 de agosto de 2010, de http://revista.inie.ucr.ac.cr/articulos/1-2002/archivos/procesos.pdf 
Chaves, Lupita. (2004). Los procesos iniciales de lecto-escritura desde la filosofía del Lenguaje Integral. Teoría y Práctica. Costa Rica: IIMEC.

Coltheart, Max. (2007). Modeling Reading: The Dual-Route Approach. En Snowling, M y Hulme, Ch. The Science of reading a Handbook. (pp. 9-20). USA: Blackwell Publishing

Costa Rica, Ministerio de Educación Pública. (1994). Política Educativa Hacia el Siglo XXI. Recuperado el día 30 de agosto de 2010, de http://www.oei.es/quipu/costarica/politicaeducativasigloXXI.pdf

Costa Rica, Ministerio de Educación Pública /OEI. (1997). Sistema Educativo Nacional de Costa Rica. Informe coordinado por Olman Ramírez Artavia. Madrid: OEl. Recuperado el día 15 de diciembre de 2010, de http://www.oei.es/quipu/costarica/

Costa Rica, Ministerio de Educación Pública. (2005). Programas de Estudio 2005. Español. I Ciclo. San José, Costa Rica: MEP.

Costa Rica, Ministerio de Educación Pública. (2010). Matricula Inicial en I y II Ciclos, por año cursado y sexo, según zona y dependencia 2010. San José, Costa Rica: Departamento de Análisis Estadístico del MEP.

Crowder, Robert. (1985). Psicología de la lectura. Madrid: Alianza Editorial.

Cuadrado, Isabel. (2008). Psicología de la Instrucción. Fundamentos para la reflexión y práctica docente. Francia: Editions Publibook.

Cuetos, Fernando, Rodríguez, María y Ruano, Eloy. (2002). Evaluación de los procesos lectores (PROLEC). España: TEA Ediciones.

Defior, Silvya, Fonseca, Liliana, Gottheil, Bárbara, Aldrey, Adriana, Jiménez, Gracia, Pujals, María, Rosa, Graciela y Dolores, Francisca. (2006). LEE. Test de lectura y escritura en español. Buenos Aires: Paidós.

Gamboa, Emma. (1962). Guía de trabajo para la maestra de primer grado con Paco y Lola. Costa Rica: Librería e imprenta Atenea.

Jiménez, Juan E. y Artiles, Ceferino. (1989) Cómo prevenir y corregir las dificultades en el aprendizaje de la lectura. Madrid: Síntesis.

León, Orfelio y Montero, Ignacio. (2003). Métodos de Investigación en Psicología y Educación (3a. ed.). Madrid: McGraw-Hill.

Lebrero, María Paz. (1992) Cómo formar buenos lectores. Madrid: Escuela Española. 
Maldonado, Antonio, Sebastián, Eugenia y Soto, Pilar. (1992). Retraso en lectura: evaluación y tratamiento educativo. Madrid: Ediciones de la Universidad Autónoma de Madrid.

Mayer, Richard. (2002). Psicología de la educación. El aprendizaje de las áreas del conocimiento. Madrid: Pearson Educación

Murillo, Rosa, Rojas, Tannia. Y Madrigal, Roxana. (1999). Diagnóstico Pedagógico: un instrumento para evaluar a escolares en las áreas de Lectura, Escritura y Aritmética (L.E.A). Costa Rica: Imprenta Cartaginesa.

Perfetti, Charles. (2001). Reading Skill. En Smelser, N and Baltes, P. International encyclopedia of the social \& behavioral sciences (pp. 12800-12805). Oxford: Pergamon

Programa Estado de la Nación (2009). Decimoquinto Informe Estado de la Nación en Desarrollo Humano Sostenible. San José: Programa Estado de la Nación.

R. de Chacón, Nora y García, Nuria. (1996). Guía Didáctica Español 1. Serie: Hacia el siglo XXI. San José: Ministerio de Educación Pública.

R. de Chacón, Nora. (1994). El método ecléctico. Una invitación para aprender a leer y escribir. Costa Rica: ALEF Editores.

Rivas, Rosa y Fernández, Pilar. (2007). Dislexia, disortografía y disgrafía. Madrid: Ediciones Pirámide

Rojas, Marta y Aguilar, Oscar. (2006) ¿Práctica de palabras o de ideas? Panorama histórico de la enseñanza del léxico en Costa Rica. Revista Educación 30 (1), 103-126.

Rojas, Emilce y Villalobos, Wilberth. (1995). Análisis de un Texto costarricense de lectoescritura. Costa Rica: Editorial Fernández-Arce

Sebastián, Eugenia y Maldonado, Antonio. (1986) El desarrollo de las estrategias de segmentación de palabras en lectores jóvenes. En J.M. Meisel (ed.). Adquisición del Lenguaje. Frankfurt: Klaus Dieter Verlag.

Sebastián, Eugenia y Maldonado Antonio. (1998) La reflexión metalingüística: Algunas consideraciones teóricas y aplicadas. Estudios de Psicología (60) 79-98.

Serrano, Francisca. (2005). Disléxicos en español: papel de la fonología y la ortografía. Tesis para optar por el grado de doctorado en XXX, Universidad de Granada, Granada, España.

Seymour, Philip. (2007). Modeling Reading: The Dual-Route Approach. En Snowling, M y Hulme, Ch. The Science of reading a Handbook. (pp. 9-20). USA: Blackwell Publishing 
Seymour, Philip, Aro, Mikko y Erskine, Jane. (2003). Foundation literacy acquisition in European orthographies. British Journal of Psychology (94), 143-174.

Snowling, Maggie y Frith, Uta. (1981) The role of sound, shape and orthographic cues in early reading. British Journal of Psychology (72), 83-87.

Viñao, Antonio. (2009) La alfabetización en España: un proceso cambiante de un mundo multiforme. En Moreno Martinez, P.L. y Navarro García, C. (coords.) Perspectivas históricas de la educación de personas adultas. España: Universidad de Salamanca. 